\title{
Comparison of the heat treatment response of SSM-HPDC 6082 and 6004 wrought alloys with A356 and F357 casting alloys
}

\author{
H. Möller ${ }^{1 a}$, G. Govender ${ }^{16}$ and W.E. Stumpr ${ }^{2 c}$ \\ ${ }^{1}$ Materials Science and Manufacturing, CSIR, Pretoria, South Africa \\ ${ }^{2}$ Department of Materials Science and Metallurgical Engineering, University of Pretoria, South \\ Africa \\ a $\underline{\text { hmoller@csir.co.za, b sgovender@csir.co.za, c waldo.stumpf@up.ac.za }}$
}

Keywords: Aluminium alloys, rheocasting, natural aging, artificial aging.

\begin{abstract}
Semi-solid metal high pressure die casting was used to produce plates from traditional wrought AlMg-Si alloys 6082 and 6004, as well as from traditional casting Al-Si-Mg alloys A356 and F357. The high Si-content of the casting alloys offer several advantages, including a faster artificial aging response, higher strength for comparable $\mathrm{Mg}$ contents and less sensitivity to prior natural aging on peak strength. However, over-aging occurs earlier in the casting alloys than in the wrought alloys.
\end{abstract}

\section{Introduction}

The Al-Si-Mg alloys that constitute the 6000 series wrought alloys and 300 series casting alloys are heat treatable and depend on age-hardening to develop enhanced strength properties [1]. The main difference between the 300 series and 6000 series is the Si content, with the casting alloys containing a significantly higher quantity [1]. Silicon promotes castability mainly because of the high fluidity imparted by the presence of large volumes of the Al-Si eutectic [1]. The lack of research on the precipitation sequence in $\mathrm{Al}-\mathrm{Si}-\mathrm{Mg}$ casting alloys compared with the $\mathrm{Al}-\mathrm{Mg}-\mathrm{Si}$ wrought alloys has recently been highlighted [2]. In Al-Si-Mg alloys in general, the decomposition of the supersaturated solid solution (SSS) is believed to occur as follows [3]: $\mathrm{SSS} \rightarrow(\mathrm{Mg}+\mathrm{Si})_{\text {clusters }}$ / GP(I) $)_{\text {spherical }} \rightarrow \beta^{\prime \prime} /$ GP $(\mathrm{II})_{\text {needles }} \rightarrow \beta_{\text {rods }}{ }^{\prime} \rightarrow \beta_{\text {plates }}$, where GP $=$ Guinier-Preston zones, $\beta=$ equilibrium $\mathrm{Mg}_{2} \mathrm{Si}, \beta^{\prime}$ and $\beta^{\prime \prime}=$ metastable precursors of $\beta$. Semi-solid metal (SSM) processing is a unique manufacturing method to produce near-net shape products for various industrial applications. The aim is to obtain a semi-solid structure which is free of dendrites and with the solid constituent present in a near spherical form. Casting alloys A356/7 are probably the most popular alloys used for SSM forming [4], but one of the main advantages of SSM processing is that it is also possible to produce near net-shape components from alloys that are conventionally wrought such as the 6000 series [5]. The purpose of this paper is to compare the aging response of 6000 series wrought alloys with A356/7 casting alloys produced with the same processing technique with the advantage of having comparable globular primary $\alpha$-Al microstructures.

\section{Experimental Procedure}

Semi-solid metal slurries of alloys 6082 and 6004 (chemical compositions are given in Table 1) were prepared using the Council for Scientific and Industrial (CSIR) rheocasting process [6]. Plates with dimensions of $6 \mathrm{~mm} \times 55 \mathrm{~mm} \times 100 \mathrm{~mm}$ were cast in steel moulds with a LK DCC130 high pressure die casting (HPDC) machine. The chemical compositions of the A356 and F357 used for comparison in this study are also indicated in Table $1[4,7]$. A solution treatment at $540^{\circ} \mathrm{C}$ for $1 \mathrm{~h}$, quenching in room temperature water, natural aging (NA) for either 0 or $120 \mathrm{~h}$, followed by artificial aging (AA) at $180^{\circ} \mathrm{C}$ was performed. Vickers hardness numbers (VHN) were determined using a $10 \mathrm{~kg}$ load from the average of four readings per sample. The tensile properties of the castings were determined using an INSTRON 1342/H1314. The dimensions of the tensile specimens can be found in reference [4]. 
Table 1: Chemical compositions in wt\% of the Al-alloys used in this study

\begin{tabular}{|c|c|c|c|c|c|c|c|}
\hline Alloy & $\mathrm{Si}$ & $\mathrm{Mg}$ & $\mathrm{Fe}$ & $\mathrm{Mn}$ & $\mathrm{Cu}$ & $\mathrm{Ti}$ & $\mathrm{Sr}$ \\
\hline 6082 & 0.82 & 0.84 & 0.22 & 0.58 & 0.03 & 0.02 & - \\
\hline 6004 & 0.47 & 0.45 & 0.16 & 0.22 & 0.02 & 0.01 & - \\
\hline A356 [7] & 7.1 & 0.36 & 0.10 & 0.01 & 0.01 & 0.07 & 0.02 \\
\hline F357 [4] & 7.0 & 0.62 & 0.10 & 0.01 & 0.01 & 0.13 & 0.02 \\
\hline
\end{tabular}

\section{Results and discussion}

Optical micrographs of SSM-HPDC alloys in the as-cast condition are shown in Fig. 1 for (a) 6082, (b) 6004, (c) A356 and (d) F357. The globular primary $\alpha$-Al that is a prerequisite for SSM processing is evident from Fig. 1.
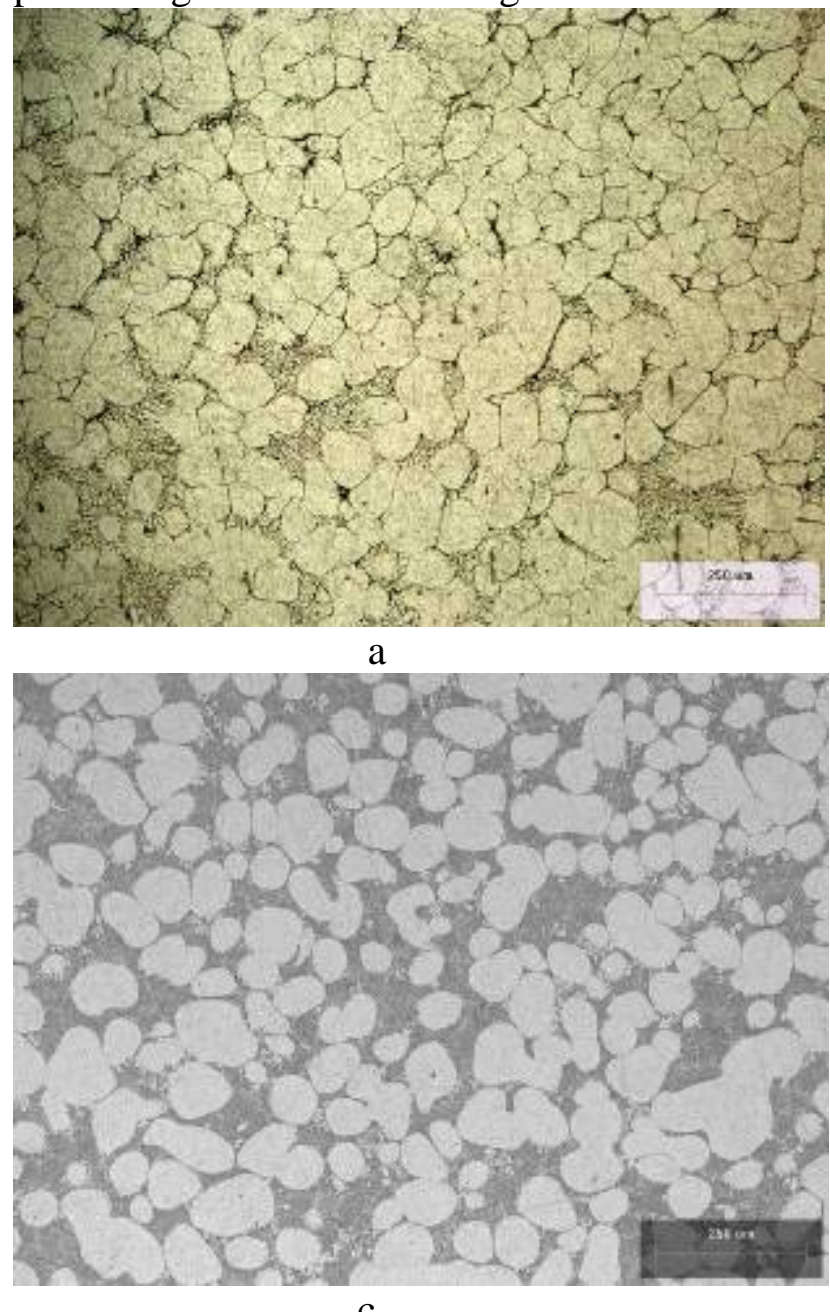

C

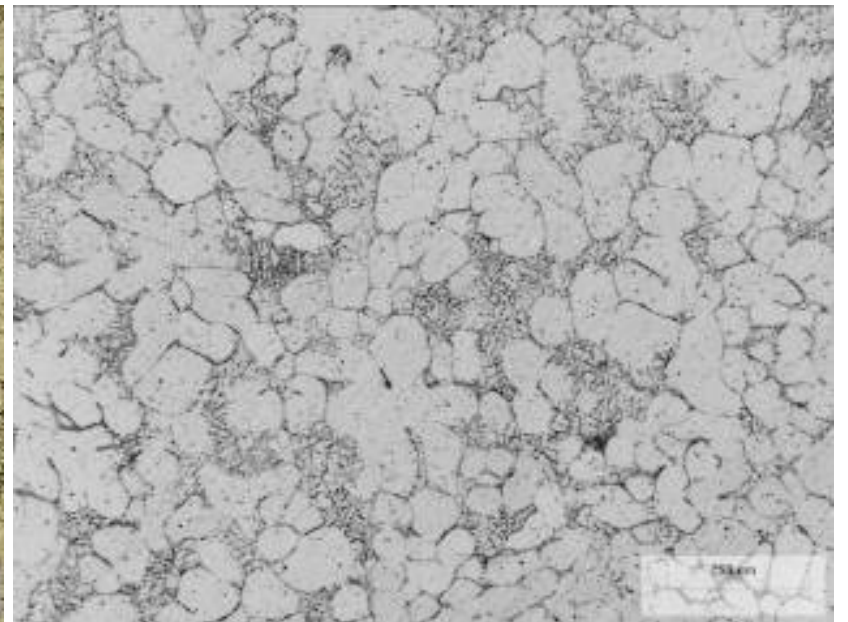

b

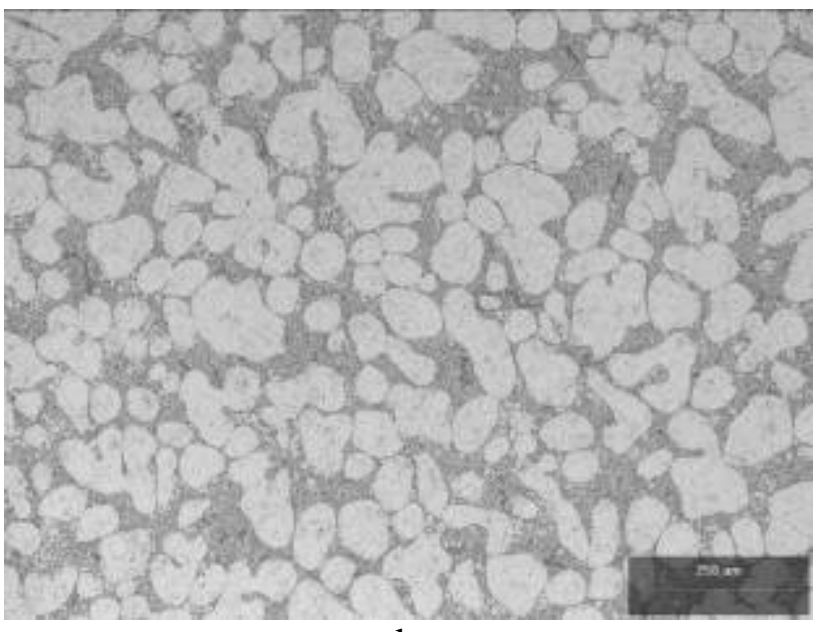

d

Figure 1: Optical micrographs of SSM-HPDC alloys in the as-cast condition for (a) 6082, (b) 6004, (c) A356 and (d) F357.

The globular primary $\alpha$-Al structure is retained in all the samples during heat treatment with spheroidisation of the eutectic silicon occurring during solution treatment in the casting alloys as shown in Fig. 2 [4,7]. Fig. 3 shows artificial aging curves, where, for the casting alloys, only A356 is shown as the behaviour of A356 and F357 is similar [4,7]. It can be seen that the same maximum hardness can be achieved in A356 regardless of the natural aging time period [7]. Alloy 6082 shows a detrimental effect of prior natural aging. This effect is well known for wrought 6082 alloys [8]. Alloy 6004 shows the opposite behaviour, with the maximum hardness being higher when natural aging occurs before artificial aging [8]. The clusters that formed during natural aging in alloy 6082 are known to be relatively stable at typical artificial aging temperature [1], as can be seen by the small initial decrease in hardness during artificial aging of the naturally aged 6082 sample 
compared to the naturally aged A356 sample in Fig. 3. The precipitates that develop directly from the clusters formed at room temperature in 6082 are coarser than those that develop in alloys aged immediately after quenching and this has a negative effect on the hardness [8]. The reverse of these processes is believed to occur in alloys such as 6004, as described in reference [9].

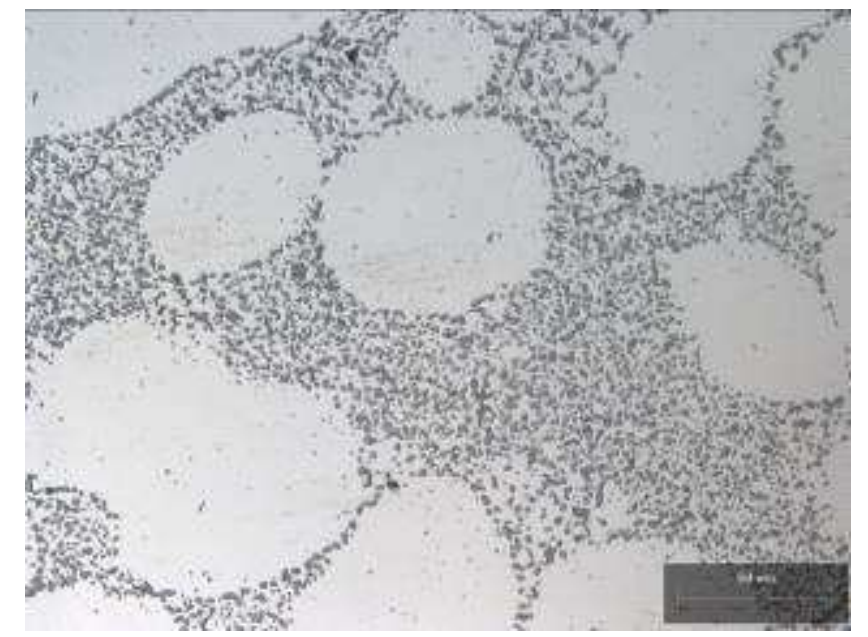

Figure 2: Optical micrograph of SSM-HPDC alloy A356 in the T6 temper condition showing spheroidisation of the eutectic Si particles.

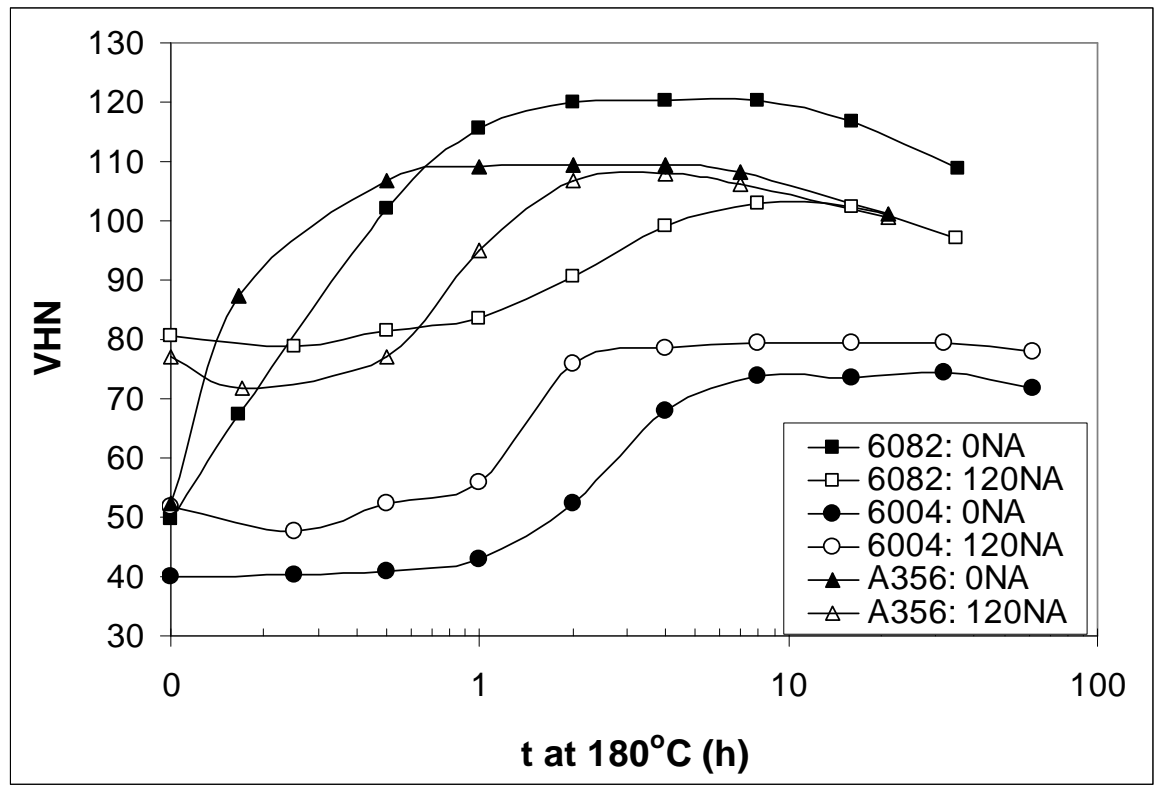

Figure 3: Artificial aging curves at $180^{\circ} \mathrm{C}$ for SSM-HPDC alloys 6082,6004 and A356 after either 0 or $120 \mathrm{~h}$ prior NA time.

It can also be seen from Fig. 3 that the hardening response of alloy A356 is rapid compared to the wrought alloys. Gupta and co-workers [10] found that excess Si (which is most pronounced in the casting alloys in this study) reduced the time to initiate strengthening. They also found that excess $\mathrm{Si}$ increases strength in both the T4 and artificially aged tempers (T6). They claimed that the improvements due to excess Si to the aging response were caused by enhanced precipitation of fine, uniformly distributed $\beta^{\prime \prime}$ particles. From Fig. 3 it is also evident that over-aging also occurs faster in A356 than the wrought 6000 series alloys. Excess Si has been claimed [10] to reduce the peak strength stability in the over-aged conditions. The reduced $\mathrm{Mg} / \mathrm{Si}$ ratio is believed to make the $\beta^{\prime \prime}$ phase less stable, and as a result, stability in strength beyond the peak aging condition is reduced [10]. The tensile mechanical properties of SSM-HPDC alloys 6082, 6004, A356 and F357 are shown in Table 2. An artificial aging time at $180^{\circ} \mathrm{C}$ of $4 \mathrm{~h}$ was used for A356 and F357 [4,7] and 8 hours for 6082 and 6004 (Fig. 3). The tensile mechanical properties are compared for samples that 
had been naturally aged for 0 or $120 \mathrm{~h}$ before artificial aging. Alloy F357 had been naturally aged for only $20 \mathrm{~h}$ before artificial aging, but the authors have shown before that no significant differences exist between $20 \mathrm{~h}$ or $120 \mathrm{~h}$ naturally aged 300 series casting samples [7]. The tensile results in Table 2 are in agreement with the aging curves of Fig. 3. The strength of SSM-HPDC 6082 is decreased significantly by a prior natural aging period, whereas alloy 6004 displays the opposite behaviour. The strengths of the casting alloys A356 and F357 are not influenced significantly by a prior NA period. It can also be seen from Table 2 that alloy 6082 has strength comparable to alloy F357 when no natural aging of the 6082 occurs and strength similar to A356 once natural aging of the 6082 occurs. However, this strength is achieved by employing double the artificial aging time at $180^{\circ} \mathrm{C}$ that was needed for the casting alloys. Also, the $\mathrm{Mg}$ requirement to achieve this strength is significantly higher for 6082 than for the casting alloys (Table 1). The ductility of the 6082 is relatively low when compared to its wrought counterpart [5] and the casting alloys (Table 2).

Table 2: $0.2 \%$ yield strength (YS), ultimate tensile strength (UTS) and \% elongation (\%A) of SSMHPDC alloys in the T6 temper condition. The standard deviation from four values for tensile properties is also indicated in brackets.

\begin{tabular}{|c|c|c|c|c|c|c|c|c|}
\hline & \multicolumn{2}{|c|}{6082} & \multicolumn{2}{c|}{6004} & \multicolumn{2}{c|}{ A356 [7] } & \multicolumn{2}{c|}{ F357 [4] } \\
\hline & 0NA & $120 \mathrm{NA}$ & 0NA & $120 \mathrm{NA}$ & 0NA & $120 \mathrm{NA}$ & 0NA & 20NA \\
\hline YS & 323 & 278 & 148 & 207 & 273 & 270 & 315 & 312 \\
{$[\mathrm{MPa}]$} & $(12.9)$ & $(6.3)$ & $(9.4)$ & $(2.2)$ & $(6.5)$ & $(5.5)$ & $(5.2)$ & $(4.1)$ \\
\hline UTS & 344 & 305 & 189 & 237 & 333 & 328 & 360 & 355 \\
{$[\mathrm{MPa}]$} & $(11.7)$ & $(10.3)$ & $(5.5)$ & $(3.0)$ & $(8.4)$ & $(5.8)$ & $(5.0)$ & $(3.9)$ \\
\hline & & & 13.1 & 12.0 & & & 5.7 & 6.0 \\
$\% \mathrm{~A}$ & $4.2(2.0)$ & $5.4(2.2)$ & $(1.0)$ & $(1.6)$ & $8.4(2.1)$ & $8.0(2.2)$ & $(1.1)$ & $(1.3)$ \\
\hline
\end{tabular}

\section{Conclusions}

Conventional casting alloys A356 and F357 obtain the same level of strength (hardness) in the T6 temper regardless of the prior natural aging period employed over a relatively wide range of $\mathrm{Mg}$ compositions. Alloy 6082 displays a much reduced strength and hardness in T6 following natural aging with alloy 6004 displaying opposite behaviour. The high Si contents of the conventional casting alloys compared to the 6000 wrought series alloys result in a faster artificial aging response, higher strength for comparable $\mathrm{Mg}$ contents and less sensitivity to prior natural aging on peak strength. However, over-aging occurs earlier in the casting alloys than for the wrought alloys.

\section{References}

[1] I. Polmear: Light alloys: from traditional alloys to nanocrystals (Butterworth-Heinemann, Amsterdam, 2006).

[2] B. Rinderer, M. Couper, X. Xiong, S. Gao and J-F. Nie: Mater. Sci. Forum Vol. 654-656 (2010), p. 590.

[3] R. Vissers, M.A van Huis, J. Jansen, H.W. Zandbergen, C.D. Marioara and S.J. Andersen: Acta Mater. Vol. 55 (2007), p. 3815.

[4] H. Möller, G. Govender, W.E. Stumpf and P.C. Pistorius: Int. J. Cast Met. Res. Vol. 23 (2010), p. 37.

[5] U.A. Curle: Trans. Nonferr. Met. Soc. China Vol. 20 (2010), p. 1719.

[6] R. Bruwer, J.D. Wilkins, L.H. Ivanchev, P. Rossouw and O.F.R.A. Damm, US Patent 7,368,690. (2008).

[7] H. Möller, G. Govender and W.E. Stumpf: Solid State Phenom. Vol. 141-143 (2008), p. 737.

[8] J. Royset, T. Stene, J.A. Saeter and O. Reiso: Mater. Sci. Forum Vol. 519-521 (2006), p. 239.

[9] C.S.T. Chang, I. Wieler, N. Wanderka and J. Banhart: Ultramicroscopy Vol. 109 (2009), p. 585.

[10] A.K. Gupta, D.J. Lloyd and S.A Court: Mater. Sci Eng. Vol. A316 (2001), p. 11. 